\title{
Influence of structural and functional features of ventricular septal defect on frontal plane QRS axis of the electrocardiogram
}

\author{
Heikki Bäckman ${ }^{1}$ \\ From the Unit of Clinical Cardiology, Department of Medicine, Royal Postgraduate Medical \\ School, London
}

Electrocardiograms were analysed and the $Q R S$ axes were determined in 179 patients with proven congenital ventricular septal defect. The average $Q R S$ axis was $+58 \cdot 0^{\circ}$ and there was no significant difference between male and female patients in the average size of the defects or the average $Q R S$ axis degree. Obvious or extreme left axis deviation was found in $10 \cdot I$ per cent and extreme left axis deviation in 3.4 per cent.

The QRS axis may occasionally be determined by the location of the defect in the intraventricular septum. Multiple ventricular septal defects tend to bring the $Q R S$ axis leftward from the average value.

Occasionally the QRS axis was not determined by the true anatomical heart axis, but in the majority right axis deviation was associated with right ventricular hypertrophy and left ventricular hypertrophy may partly be responsible for left axis deviation in some patients. There was no significant dependence of the $Q R S$ axis upon the hypertrophy of crista supraventricularis observed at cardiotomy.

The dependence of right axis deviation upon total pulmonary resistance was of borderline significance but was not significant in left axis deviation. When associated with a normal axis or left axis deviation, right ventricular hypertrophy was dependent on the haemodynamic findings to a varying degree. This was not a constant finding in patients with right axis deviation. The dependence of left ventricular hypertrophy upon the left-to-right shunt was of borderline significance when associated with left axis deviation.

Obvious or extreme left axis deviation was occasionally associated with severe pulmonary vascular disease in congenital ventricular septal defect and cannot therefore be relied upon to differentiate the individual patients.

In the adult a shift of the frontal QRS vector toward the left with increasing age has been shown in a young population of asymptomatic persons (Harlan, Graybiel, and Osborne, 1965). In normal infants and children however the rightward orientation of the frontal QRS vector is consistent with the relative hypertrophy of the right ventricle, and leftward movement of QRS axis indicates an abnormality.

The incidence of left axis deviation in ventricular septal defect is difficult to judge while the series of patients with congenital heart disease, though mostly composed of infants and children, may contain young adults Received 19 May 197 I.

${ }^{1}$ Supported by a grant from Duodecim (Societas Medicorum Fennica). Present address: Department of Medicine, Central Hospital, Mikkeli, Finland.
(Brink and Neill, 1955). Also, no special characteristics were reported in patients with left axis deviation and ventricular septal defect (Prato and Bouchard, 1964).

In the present series the incidence of left axis deviation has been studied in patients with proven ventricular septal defect in order further to evaluate the relation of QRS axis degree and electrocardiographic evidence of ventricular hypertrophy with the anatomical and haemodynamic abnormalities.

\section{Patients and methods}

The series consists of 179 patients with congenital ventricular septal defect who were investigated and operated upon at the Royal Postgraduate Medical School by Mr. W. P. Cleland and Professor $H$. Bentall between 1958 and 1966 . There were 106 male and 73 female patients ranging 
from 2 to 57 years of age. The mean age was II. 5 years and 80 per cent of the patients were 15 years of age or less at the time of the operation.

For orientation the location of the defect in the ventricular septum was classified as proposed by Becu et al. (1956). The size of the defect was measured at its greatest diameter. In ro patients the size was estimated and in these patients the criteria given by Goodwin (1960) were applied. In 3 patients no size of the defect was given.

Criteria for electrocardiographic analysis The QRS axis was determined in the frontal plane in standard electrocardiograms in lead I and lead III and the vector analysis was obtained by the Bayley triaxial reference diagram (1943). The normal axis position was taken as $+90^{\circ}$ to $+31^{\circ}$. With higher positive values, right axis deviation - was diagnosed. Left axis deviation was considered to be present when the manifest vector was $+30^{\circ}$ or less. For grading of the severity of left axis deviation the criteria given by Lepeschkin (I95I) were applied.

The electrocardiographic diagnosis of right ventricular hypertrophy was made using the criteria of Hollman (1958) for infants and children up to I5 years of age; otherwise the criteria of Sokolow and Lyon (1949) were employed. The voltage of the $R$ wave was also measured in aVR and $V_{4} R$ and correspondingly of the $S$ wave in $V I$ and in $V_{5}$ or V6 leads. $0.03 \mathrm{sec}$ was taken as the upper limit of normal for the time of onset of the intrinsicoid deflection in right praecordial leads. The severity of the right ventricular hypertrophy was assessed by the criteria given by Goodwin and Abdin (1959). ${ }^{1}$

The criteria of Pagnoni and Goodwin (1952) were used for the diagnosis of the left ventricular hypertrophy. If the $S$ wave in aVR equalled is $\mathrm{mm}$ or more, $20 \mathrm{~mm}$ was taken as an upper normal limit for the $R$ wave in V6 (V5). Otherwise $26 \mathrm{~mm}$ was considered as the upper normal limit for the $\mathbf{R}$ wave in this lead. In addition the Lewis index was calculated, taking $+17 \mathrm{~mm}$ or a greater value to indicate left ventricular hypertrophy (Holzmann, 196I). ${ }^{2}$ The criteria described by

1 Grade I: Dominant $R$ wave in lead $V_{4} R$ or dominant $\mathrm{S}$ in $\mathrm{V}_{5}$.

Grade 2: Dominant $R$ wave in $V_{4} R$ and $V_{I}$ or dominant $R$ in $V_{4} R$, with dominant $S$ in $V_{5}$ or $R$ in aVR.

Grade 3: Dominant $R$ in $V_{4} R, V_{1}$, and aVR, with dominant $\mathrm{S}$ in $\mathrm{V}_{5}$.

- Grade 4: Dominant or monophasic $R$ in $V_{4} R$ of 10 $\mathrm{mm}$ or more, with or without $\mathrm{qR}$ pattern; dominant $\mathrm{R}$ in $\mathrm{V}_{\mathbf{r}}$; dominant $\mathrm{S}$ in $\mathrm{V}_{5}$; with or without dominant $R$ in aVR, and $T$ inversion in right praecordial leads.

2 The grading for the severity of left ventricular hypertrophy used in the Unit of Clinical Cardiology at the Royal Postgraduate Medical School has been em- ployed. Grade I applies to voltage changes only. In Grade 2 additional RS-T depression and slight $\mathrm{T}$ wave inversion in aVL and left praecordial leads are present, combined with a horizontally placed heart. In Grade 3 appreciable $T$ wave inversion in left praecordial leads is present. Grade 4 has deep T wave inversion, greater than Grade 3.
Pagnoni and Goodwin (1952) were applied for the diagnosis of combined ventricular hypertrophy.

The haemodynamic findings used to correlate with the QRS axis deviation represent values obtained preceding cardiac surgery.

\section{Results}

The QRS axis deviation according to the location of the ventricular septal defect is summarized in Table I. Eleven of 179 patients $(6 \%)$ had supracristal defects lying between the crista supraventricularis and the annulus fibrosus of the pulmonary valve. In I4I patients $(79 \%)$ the defect was situated inferior and posterior to the crista supraventricularis in the right ventricular outflow tract. In both groups the average axis value for QRS was in the normal range with a low standard error of the mean. In 152 patients ( $85 \%$ ) who had the defect located supra- or infracristal in the right ventricular outflow tract, the average QRS axis was $+64 \cdot 2^{\circ}$, with a standard deviation of 54.7 and a standard error of the mean of 4.4 . Seventeen patients $(9 \%)$ had the defect in an area not related to the right ventricular outflow tract with the average QRS axis of $+17 \cdot 4^{\circ}$. The standard deviation was $63 \cdot 1$ and the standard error of the mean $15 \cdot 3$. One patient had a single ventricle and the QRS axis of $-64^{\circ}$. In the whole series, 9 patients $(5 \%)$ had two or more ventricular septal defects. Of 7 patients with two defects, 3 had left axis deviation and a QRS axis of $-14^{\circ}$, $-33^{\circ}$, and $-50^{\circ}$ respectively, 3 had a normal axis, and I had right axis deviation. Three ventricular septal defects were found in 2 patients and both of them had a normal axis position.

In 88 of 176 patients $(50 \%)$ the greatest diameter of the defect was between I I and 20 $\mathrm{mm}$. In this group, 25 patients had right axis and 20 patients left axis deviation. The greatest diameter exceeded $20 \mathrm{~mm}$ in 52 patients $(29 \%)$. In this group right axis deviation was present slightly more frequently than left axis deviation. The opposite was found in 33 patients (19\%) whose defects were small and measured between 5 and Io $\mathrm{mm}$. In these patients left axis deviation was met four times more frequently than right axis deviation. Only 3 patients ( $2 \%$ ) had small defects less than $5 \mathrm{~mm}$ in diameter, and the QRS axis of $+160^{\circ},+74^{\circ}$, and $-9^{\circ}$ respectively each. The average size of the defects in IOI male patients was $20.3 \mathrm{~mm}$, and in 65 female patients $18.5 \mathrm{~mm}$ in greatest diameter with a small standard deviation and a minimal standard error of mean. The average QRS axis deviation was $53.5^{\circ}$ and $60.9^{\circ}$ correspondingly, 
TABLE I Site of defect and distribution of frontal $Q R S$ vector axis in 179 patients with ventricular septal defect

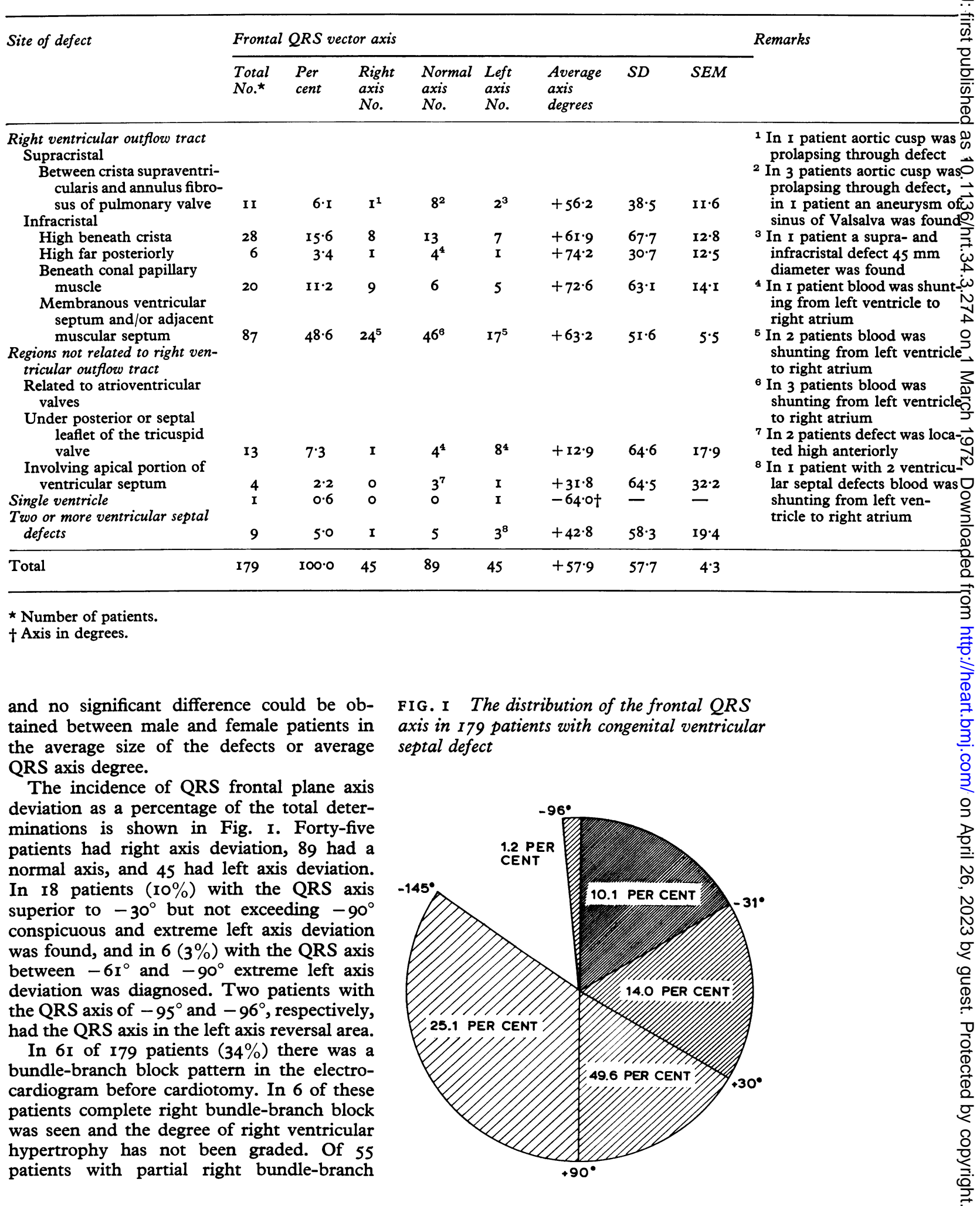


block, 14 had right axis deviation, 28 a normal axis, and 13 had left axis deviation. After exclusion of the 6 patients with complete right bundle-branch block, 173 are left for electrocardiographic analysis of ventricular hypertrophy

Evidence of isolated right ventricular hypertrophy with or without hypertrophy of the crista supraventricularis was found in 38 out of 173 patients $(22 \%)$. In 22 out of 118 patients $(19 \%)$ with no signs of right bundlebranch block in the electrocardiogram isolated right ventricular hypertrophy was observed. In I I 7 out of 173 patients $(68 \%)$ right ventricular hypertrophy either isolated or hypertrophy of both ventricles was found.

- Additionally, 7 patients with left axis deviation and right ventricular hypertrophy had evidence of combined ventricular hypertrophy. Ten of 31 patients with hypertrophy of the crista supraventricularis as described at operation had partial, and 3 had complete right bundle-branch block.

Isolated left ventricular hypertrophy was found in 28 out of 173 patients ( $16 \%$ ) and isolated left ventricular hypertrophy or hypertrophy of both ventricles respectively in 107 patients $(62 \%)$. In 2 more patients right axis deviation and left ventricular hypertrophy were found associated. Biventricular hypertrophy was met in 79 patients $(45 \%)$ and no electrocardiographic evidence of ventricular hypertrophy in 19 patients ( $11 \%$ ).

In 40 out of 42 patients (95\%) with right axis deviation, right ventricular hypertrophy of grade I-4 limits was found (Fig. 2). Of the 42 patients, $19(45 \%)$ also had isolated left ventricular or biventricular hypertrophy. The difference in the incidence of right and left ventricular hypertrophy in these patients is highly significant $(\mathbf{P}<0.00 \mathrm{I})$. In patients with a normal axis and those with left axis deviation the difference obtained similarly in the appearance of right or left ventricular hypertrophy was not significant. In 28 of 44 patients $(64 \%)$ with left axis deviation, right ventricular hypertrophy of grade I-4 limits was found, and in 31 of these 44 patients $(70 \%)$ left ventricular or biventricular hypertrophy was present.

The average values for $Q R S$ axis degree and the haemodynamic findings according to the resting - levels are summarized in Table 2. The QRS vector progressively shows a shift toward the right as the pulmonary vascular resistance increases and the left-to-right shunt values become smaller. The distribution of the QRS

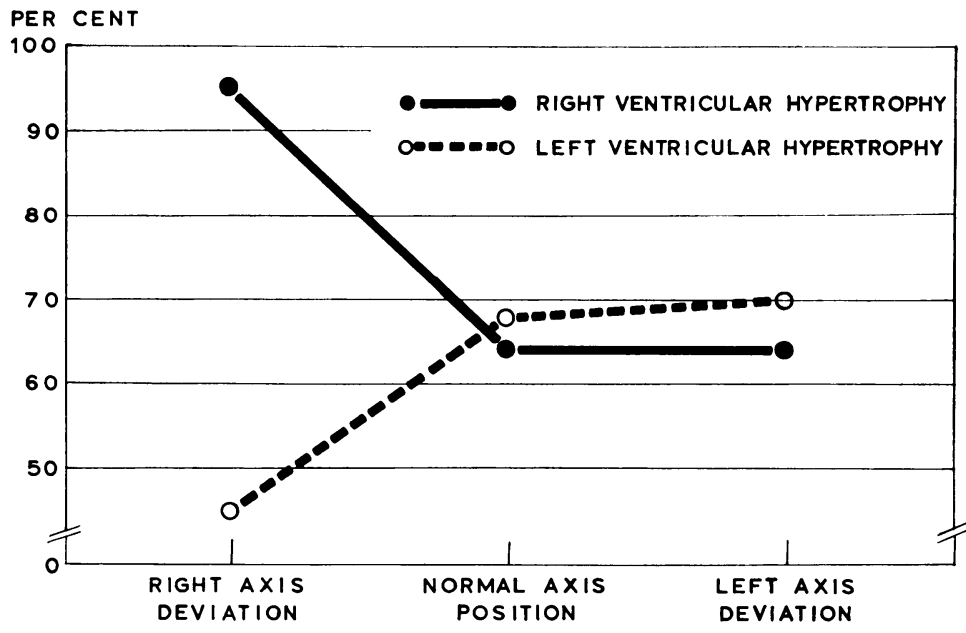

FIG. 2 The difference obtained in the incidence of right ventricular and left ventricular hypertrophy according to $Q R S$ axis deviation.

axis according to the haemodynamic measurements is set out in Fig. 3. In 155 of 159 patients $(97 \%)$ the ratio of pulmonary artery flow to systemic flow exceeded I. The right ventricular systolic pressure exceeded $25 \mathrm{~mm}$ $\mathrm{Hg}$ in 165 of 170 patients $(97 \%)$. The pulmonary artery mean pressure exceeded 22 $\mathrm{mmHg}$ in $\mathrm{IIO}$ of 172 patients $(64 \%)$ and the

FIG. 3 The incidence of raised values for haemodynamic measurements related to the total determinations in the corresponding group of patients according to $Q R S$ axis deviation. For the number of patients in the four groups, see text.

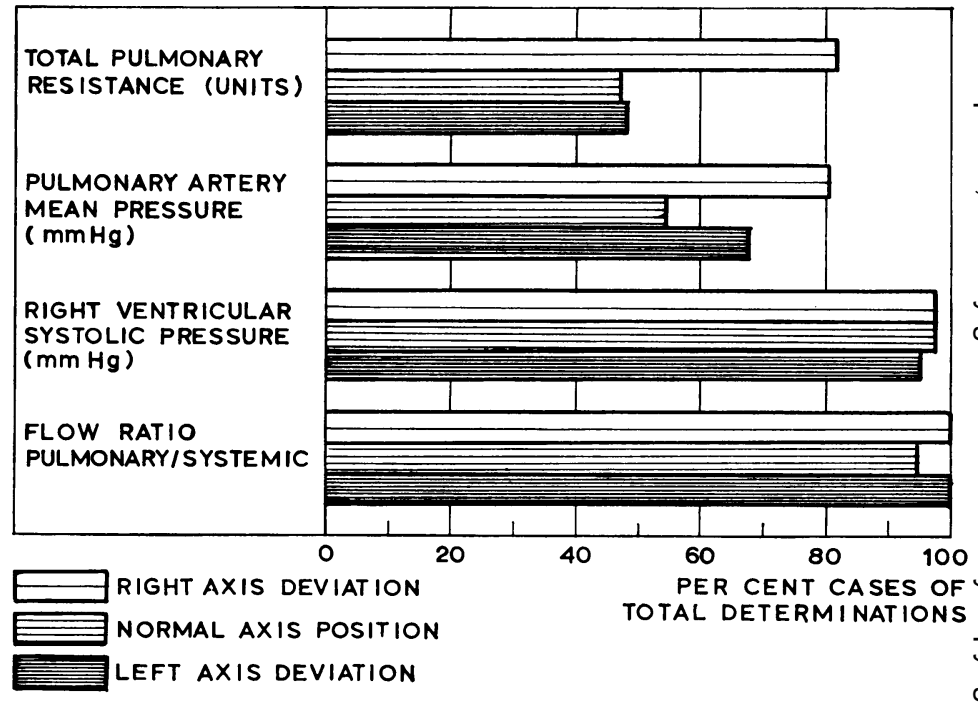


total pulmonary resistance 2.5 units in 74 of 128 patients $(58 \%)$. The significance of the difference in these measurements in patients with right axis and left axis deviation and in the left-to-right shunt, respectively, is given in Table 3. In 12 of 38 patients $(32 \%)$ with right axis and in 5 of 31 patients ( $16 \%$ ) with left axis deviation the total pulmonary resistance was 7 or more units. In patients with right axis the dependence of $Q R S$ axis degree upon total pulmonary resistance was about significant $(P<0.05)$ but respectively not significant in the patients with left axis deviation. No significant dependence of QRS axis degree upon the other haemodynamic measurements was obtained.

The dependence of right ventricular hypertrophy upon right ventricular systolic pressure was highly significant $(P<0.001)$ in 42 patients with left axis deviation and in 82 patients with a normal axis; in $4 \mathrm{I}$ patients with right axis deviation it was about significant $(\mathbf{P}<0.05)$. Respectively, the dependence upon pulmonary artery mean pressure was significant $(\mathrm{P}<0.01)$ in 42 patients with left axis deviation and highly significant $(P<0.00 \mathrm{I})$ in 86 patients with a normal axis, but not significant in 38 patients with right axis deviation. When these correlations were made only in patients with the pressure gradient between the right ventricle and pulmonary artery not exceeding $20 \mathrm{mmHg}$ and with no signs of pulmonary stenosis, a highly significant $(P<0.001)$ dependence of right ventricular hypertrophy upon pulmonary artery mean pressure was also found in 39 patients with left axis deviation. The dependence of right ventricular hypertrophy upon total pulmonary resistance was about significant $(P<0.05)$ only in 27 patients with left axis deviation and no signs of pulmonary stenosis. Of II3 patients, in 26 respectively the dependence of left ventricular hypertrophy upon the left-toright shunt was just significant $(P<0.05)$ but

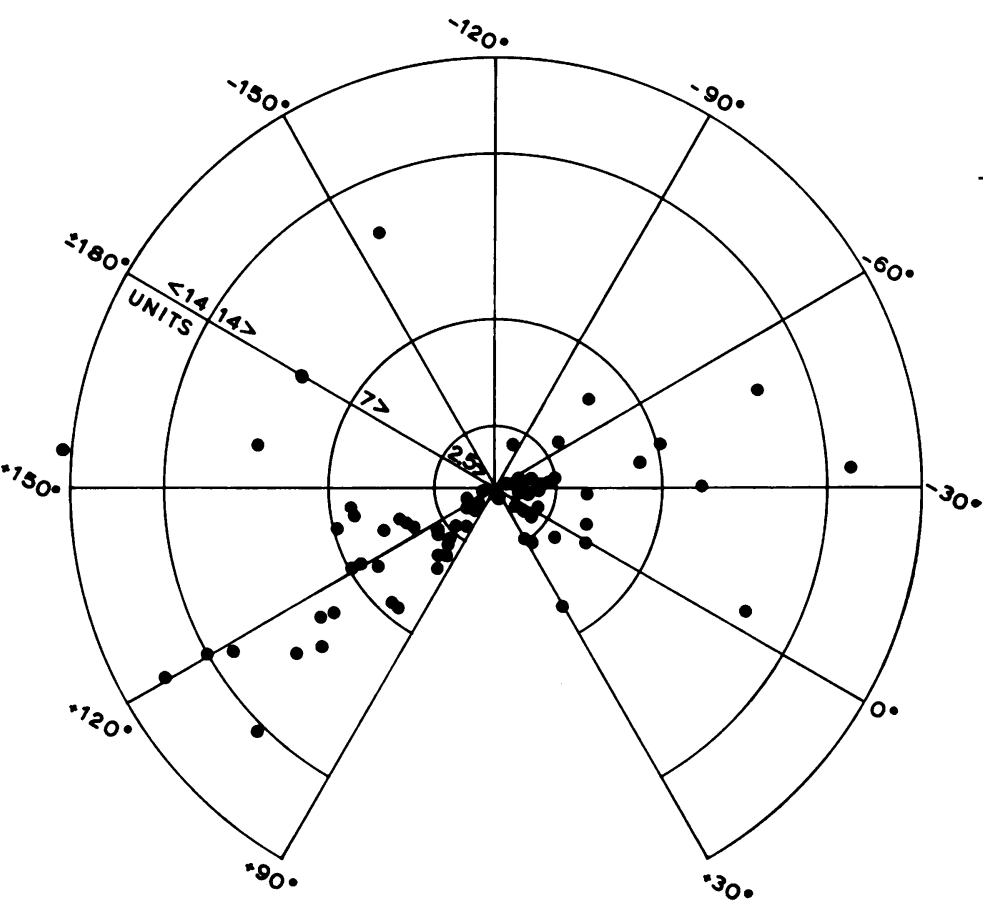

FIG. 4 The $Q R S$ axis degree in patients with right and left axis deviation related to the measurements of total pulmonary resistance (each dot represents one patient).

was not significant in 56 patients with a normal axis or 31 patients with right axis deviation.

\section{Discussion}

The incidence of left axis deviation in ventricular septal defect varies partly due to the limits accepted for the QRS axis degree (Toscano-Barboza and DuShane, I959; Prato and Bouchard, 1964; Pryor and Blount, 1966). The results of Kulbertus, Coyne, and

TABLE 2 Average frontal $Q R S$ vector axis and left-to-right shunt in patients with ventricular septal defects grouped according to haemodynamic findings at rest

\begin{tabular}{|c|c|c|c|c|c|c|c|c|}
\hline & \multicolumn{4}{|c|}{ Right ventricular systolic pressure $(\mathrm{mmHg})$} & \multicolumn{4}{|c|}{ Pulmonary artery mean pressure $(\mathrm{mmHg})$} \\
\hline & $<25$ & $<50$ & ₹100 & ₹150 & $\gtrless 22$ & $\gtrless 50$ & $<70$ & $\gtrless 90$ \\
\hline $\begin{array}{l}\text { No. of patients } \\
\text { Average age (yr) } \\
\text { Average frontal QRS vector }\end{array}$ & $\stackrel{5}{11 \cdot 6}$ & $\begin{array}{l}53 \\
12 \cdot 1\end{array}$ & $\begin{array}{l}94 \\
11 \cdot 8\end{array}$ & $\begin{array}{l}18 \\
9 \cdot 7\end{array}$ & $\begin{array}{l}62 \\
13.9\end{array}$ & $\begin{array}{l}65 \\
10.5\end{array}$ & $\begin{array}{c}30 \\
9 \cdot 1\end{array}$ & $\begin{array}{l}\text { I5 } \\
11 \cdot 5\end{array}$ \\
\hline $\begin{array}{l}\text { axis in degrees } \\
\text { SD } \\
\text { SEM }\end{array}$ & $\begin{array}{r}+32 \cdot 4 \\
62 \cdot 7 \\
28 \cdot 0\end{array}$ & $\begin{array}{r}+39 \cdot 3 \\
47 \cdot 5 \\
6 \cdot 5\end{array}$ & $\begin{array}{r}+60 \cdot 8 \\
61 \cdot 9 \\
6 \cdot 4\end{array}$ & $\begin{array}{r}+89 \cdot 3 \\
48 \cdot 4 \\
I I \cdot 4\end{array}$ & $\begin{array}{r}+53 \cdot 2 \\
47 \cdot 5 \\
6.0\end{array}$ & $\begin{array}{r}+49 \cdot 5 \\
60 \cdot 1 \\
7 \cdot 5\end{array}$ & $\begin{array}{r}+65 \cdot 7 \\
66 \cdot 2 \\
12 \cdot 1\end{array}$ & $\begin{array}{r}+68 \cdot 4 \\
59 \cdot 0 \\
15 \cdot 2\end{array}$ \\
\hline Average left-to-right shunt (1.) & $2 \cdot 3(2)^{\star}$ & $5.9(39)$ & $5 \cdot 6(65)$ & $5.6(16)$ & $5 \cdot 7(47)$ & $6 \cdot 0(40)$ & $4 \cdot 3(20)$ & $5.6(14)$ \\
\hline
\end{tabular}


Hallidie-Smith (1969) working in the same Unit for lone left axis deviation $(2 \%)$ and left axis deviation associated with right bundlebranch block $(6 \%)$ are similar to the results found in this series for conspicuous and extreme left axis deviation. It is evident that the extremes of QRS axis deviation pointing leftward may vary considerably with age, and in ventricular septal defect the incidence of extreme left axis deviation slightly exceeds the I. 4 per cent incidence found for healthy infants and children (Gup, Franklin, and Hill, 1965). The mean age in the three groups of patients analysed according to QRS axis deviation did not reveal any significant differences, and the male-to-female ratio, respectively $3: 2$, was of the same order. More than half of the patients had the QRS axis between $0^{\circ}$ and $+90^{\circ}$.

In the largest group of patients with the defect occurring in the membranous ventricular septum or adjacent muscular septum the QRS axis did not usually differ much from the arithmetical mean found, respectively, for healthy children and adolescents (Wershing and Walker, 1963). The conduction tissue was found to be closely related to the margin of the ventricular septal defect (Lev, 1960; Titus, Daugherty, and Edwards, 1963) and to the surrounding fibres of the conduction tissue of the midseptal defects in a varying amount. - Evidently the defect does not affect the QRS axis significantly when located in the right ventricular outflow tract. If located posterior to the papillary muscle of the conus the defect lies beneath the septal leaflet of the tricuspid valve. In this site of the defect left axis deviation was relatively more common. Accordingly, Leachman and Wolfe (1968) also considered this association to be frequent. The number of patients in this group was 13 , and the two groups are therefore not quite comparable. Nevertheless, the difference in the pointing of the $\mathrm{QRS}$ axis based on the location
TABLE 3 Significance of difference in average values of haemodynamic measurements in patients with right and left axis deviation

\begin{tabular}{lll}
\hline$R S$ axis deviation & $\begin{array}{l}\text { Significance of } \\
\text { difference }\end{array}$ \\
\cline { 2 - 3 } & $\frac{145^{\circ}-+92^{\circ}+30^{\circ}--96^{\circ}}{t} P \dagger$
\end{tabular}

\begin{tabular}{|c|c|c|c|c|}
\hline $\begin{array}{l}\text { Ratio of pulmonary artery } \\
\text { flow to systemic flow }\end{array}$ & $2 \cdot 4(42)^{\star}$ & $2 \cdot 4(38)$ & 0.21 & - \\
\hline $\begin{array}{l}\text { Right ventricular systolic pres- } \\
\text { sure (mmHg) }\end{array}$ & $85 \cdot 4(44)$ & $57 \cdot 5(43)$ & 4.95 & $<0.001$ \\
\hline $\begin{array}{l}\text { Pulmonary artery mean pres- } \\
\text { sure (mmHg) } \\
\text { Total pulmonary resistance }\end{array}$ & $46 \cdot 9(4 I)$ & $33.9(43)$ & $2 \cdot 72$ & $<0.01$ \\
\hline $\begin{array}{l}\text { (units) } \\
\text { Left-to-right shunt (1.) }\end{array}$ & $\begin{array}{l}6.5(38) \\
5.7(38)\end{array}$ & $\begin{array}{l}3.9(31) \\
5.8(29)\end{array}$ & $\begin{array}{l}2.69 \\
0.13\end{array}$ & $\leq 0.01$ \\
\hline
\end{tabular}

* Number of patients.

† Significance level.

of the defect was significant at the I per cent level, and it seems likely that left axis deviation to some extent may depend upon the site of the defect.

On occasion conspicuous and extreme left axis deviation was observed in association with the usual variety of ventricular septal defect. Out of 18 patients this was found in 5 who had the defect in the membranous septum and in 2 who also had a second defect in the muscular septum. In 6 patients the defect occurred beneath the tricuspid valve. Two patients had high infracristal defects, $25 \mathrm{~mm}$ and $50 \mathrm{~mm}$ in diameter, respectively; I had a muscular infracristal and $I$ a supracristal defect, both of $20 \mathrm{~mm}$ in diameter; and I had a single ventricle. A typical electrocardiogram with left axis deviation and counterclockwise rotation of the QRS loop in the frontal plane similar to the recordings found in the atrioventricular canal (Toscano-Barboza and DuShane, 1959; Lambert, Kelsch, and Vlad,

\begin{tabular}{|c|c|c|c|c|c|}
\hline \multicolumn{4}{|c|}{ Total pulmonary resistance } & \multicolumn{2}{|c|}{$\begin{array}{l}\text { Ratio of pulmonary artery flow to } \\
\text { systemic flow }\end{array}$} \\
\hline$<2.5$ & $<7$ & ₹I4 & $>\mathrm{I} 4$ & $1-3: 1$ & $4-6: I$ \\
\hline $\begin{array}{r}54 \\
14.7 \\
+45.7\end{array}$ & $\begin{aligned} 50 \\
11 \cdot 2 \\
+70 \cdot 0\end{aligned}$ & $\begin{array}{r}20 \\
9 \cdot 0 \\
+58.4\end{array}$ & $\begin{array}{r}4 \\
9 \cdot 8 \\
+86 \cdot 5\end{array}$ & $\begin{array}{r}137 \\
12.5 \\
+56.3\end{array}$ & $\begin{array}{r}22 \\
9.5 \\
+72.5\end{array}$ \\
\hline $\begin{array}{l}50 \cdot 2 \\
6 \cdot 8 \\
7 \cdot 4(53)\end{array}$ & $\begin{array}{l}5 \mathrm{I} \cdot 2 \\
7 \cdot 2 \\
4 \cdot 8(46)\end{array}$ & $\begin{array}{l}79 \cdot 2 \\
17 \cdot 7 \\
2 \cdot 9(18)\end{array}$ & $\begin{array}{l}82 \cdot 5 \\
4 I \cdot 2 \\
2 \cdot 0(4)\end{array}$ & $\begin{array}{l}55 \cdot 5 \\
4.7 \\
5.1 \text { (II } 3)\end{array}$ & $\begin{array}{l}61 \cdot 4 \\
13 \cdot 1 \\
12 \cdot 3(13)\end{array}$ \\
\hline
\end{tabular}


1963) is also encountered in ventricular septal defects with the upper edge of the defect not bordered by muscle but rather by the tricuspid ring (Burchell, DuShane, and Brandenburg, 1960; Feldt, DuShane, and Titus, 1966). In I of the 2 patients with the QRS axis in the left axis reversal area, the posterior rim of the defect was formed by a ridge between the aorta and the additional bicuspid valve, but of I I patients with a communication between the left ventricle and right atrium none had conspicuous or extreme left axis deviation. The average QRS axis of $+54.8^{\circ}$ in these patients was slightly leftward from $+58.0^{\circ}$ obtained for the entire series. Therefore, it is not possible to prove the site of the defect by electrocardiographic recording.

Left axis deviation is not infrequently associated with large ventricular septal defects exceeding $20 \mathrm{~mm}$ in diameter, but this is not a constant finding. There were 16 patients with right axis and 12 patients with left axis deviation and the defect of this size, and the average diameters of the defects $30.6 \mathrm{~mm}$ and $3 \mathrm{I} \cdot 3 \mathrm{~mm}$, respectively. Relatively more left axis than right axis deviation was associated with small defects, $10 \mathrm{~mm}$ or less in diameter. The left axis also tended to have a negative and the right axis a positive dependence upon the size of the defect, but this was of borderline significance $(P<0.05)$ obtained only in patients with a normal axis position.

In patients with an atrioventricular canal type of QRS loop associated with ventricular septal defect the morphological changes of the specific conduction tissue have been suggested as a basic explanation for the electrocardiographic features (Feldt et al., 1966). The anatomical configuration allows an early excitation of the left bundle-branch and activation of the posterobasal portion of the septum. In addition, a delay of 20 to $30 \mathrm{msec}$ has been shown in the activation process at the upper third of the left septal mass and at the high anterolateral regions of the free left ventricular wall after interruption of the anterior subdivision of the left bundle-branch (Medrano et al., 1970). The ventricular activation time as measured in praecordial complexes is, at operation, shown to be related to adjacent epicardial excitation (Durrer, 1968). Therefore, an increase in the Q-R interval appears to be associated with an interruption of the anterior subdivision of the left bundle. Only in one patient with two high infracristal defects and evidence of third degree left ventricular hypertrophy was this found where the Q-R interval was $0.06 \mathrm{sec}$ in lead V6. In all other patients with left axis deviation the ventricular activation time was $0.04 \mathrm{sec}$ or less, respectively. Further, there was no sign of an interruption of the entire arborization of the left bundle-branch (Castellanos and Lemberg, 1969), and a $Q$ wave of varying size was present in one or more of leads $V_{5}$ to $V_{7}$ in 39 of 45 patients with left axis deviation.

There was a 7.8 per cent incidence of left axis deviation associated with right bundlebranch block. This clinical entity was originally considered pathognomonic of an endocardial cushion defect (Feldt et al., 1966). In adults, disregarding the causal disease, the two findings combined may involve an atrioventricular conduction delay (Rosenbaum et al., 1969), but they can appear without any degree of atrioventricular block. This was found in only one patient with left axis deviation associated with a $P-R$ prolongation to $0.26 \mathrm{sec}$ in lead II and a ventricular septal defect in the usual site. Possibly this gives support to the observation that an occasional interruption of the specific conduction pathway may influence the ventricular activation

TABLE 4 Incidence of ventricular hypertrophy by electrocardiographic manifestations in four studies of ventricular septal defects

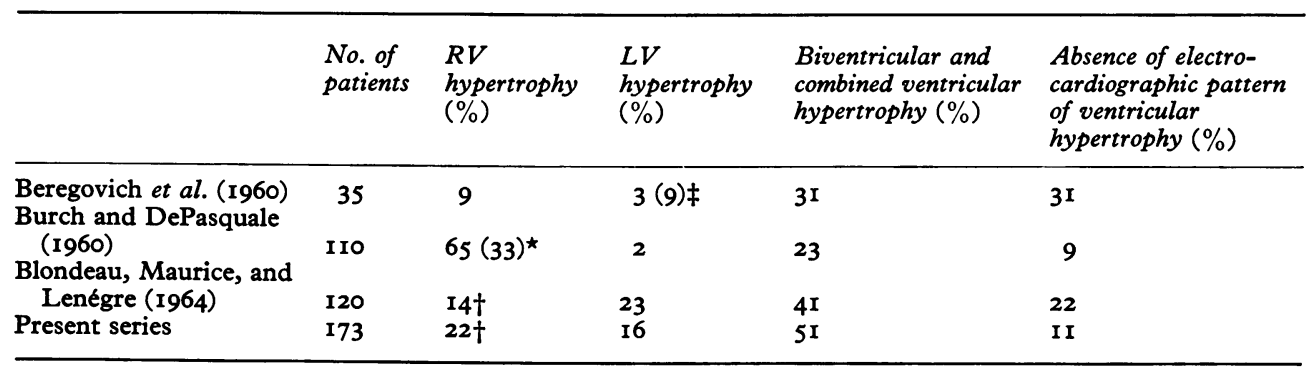

$\star \mathbf{R S R}^{\prime}$ pattern only.

† Isolated right ventricular hypertrophy.

$¥$ By voltage changes and marked left axis deviation. 
TABLE 5 Difference in haemodynamic findings in patients with right axis deviation and severe pulmonary vascular disease and patients with conspicuous and extreme left axis deviation

\begin{tabular}{|c|c|c|c|c|c|c|c|}
\hline \multirow[t]{2}{*}{$Q R S$ axis deviation } & \multirow[t]{2}{*}{$\begin{array}{l}\text { No. of } \\
\text { patients }\end{array}$} & \multicolumn{2}{|c|}{$\begin{array}{l}\text { Pulmonary artery } \\
\text { mean pressure }(\mathrm{mm} H g)\end{array}$} & \multicolumn{2}{|c|}{$\begin{array}{l}\text { Total pulmonary } \\
\text { resistance (units) }\end{array}$} & \multicolumn{2}{|c|}{$\begin{array}{l}\text { Left-to-right shunt } \\
(\text { l. })\end{array}$} \\
\hline & & Range & Average & Range & Average & Range & Average \\
\hline $\begin{array}{l}-145^{\circ}-+104^{\circ} \\
-31^{\circ}--90^{\circ} \\
\text { Significance of difference }\end{array}$ & $\begin{array}{l}12 \\
18\end{array}$ & $\begin{array}{r}28-88 \\
4-72\end{array}$ & $\begin{array}{l}67.6 \\
33.8 \\
<0.001\end{array}$ & $\begin{array}{l}8 \cdot 7-18 \cdot 3 \\
0 \cdot 4-15 \cdot 0\end{array}$ & $\begin{array}{c}12 \cdot 1 \\
4.6 \ddagger \\
<0.001\end{array}$ & $\begin{array}{l}0.7-5.0 \\
0.7-9.4\end{array}$ & $\begin{array}{r}2.5 \dagger \\
4.4 \ddagger \\
<0.05\end{array}$ \\
\hline
\end{tabular}

$\star$ Significance level $=\mathbf{P}$ value.

$\dagger$ No. $=11$.

$\ddagger$ No. $=\mathbf{I 2}$.

significantly in ventricular septal defects. .Only in 3 of 14 patients with left axis deviation and associated right bundle-branch block was the defect not of the common type; in 2 the blood was shunting from the left ventricle to the right atrium, and I patient had the single ventricle.

It is evident that chamber enlargement can influence the QRS axis significantly. In the majority, right axis deviation was associated with right ventricular hypertrophy, especially in patients with hypertrophy of severe degree. In addition, there was a highly significant difference at the 0.1 per cent level in the incidence of right and left ventricular hypertrophy in patients with right axis deviation, but the dependence of QRS axis degree upon the hypertrophy of crista supraventricularis observed at cardiotomy was not significant. Nevertheless, the dependence of QRS axis degree upon ventricular hypertrophy recorded in standard limb leads or praecordial leads may be misleading, as there is a tendency to underdiagnose the enlargement of the heart due to cancellation of the voltage over both 'ventricles. Coleman (1962) also concluded that the electrical axis might, on occasion, give more reliable evidence of ventricular hypertrophy than the praecordial leads. In this series the combined ventricular hypertrophy, which includes the QRS axis as one electrocardiographic criteria, was more con- stantly dependent upon the ventricular hypertrophy observed at cardiotomy than what was, respectively, found for biventricular hypertrophy.

The frequency of left ventricular hypertrophy may be high when related to some results (Table 4), though the maximum normal - range used for the $R$ wave voltage in lead V6 is comparable with the values of other studies (Burch and DePasquale, 1967). The $S$ wave voltage in aVR, which was also measured, represents a mixture of potentials from right and left ventricular cavities (Hecht, 1946).
In addition, no false positive recording has been obtained when this reference lead for left ventricular hypertrophy has been used (Romhilt et al., 1969). An S wave of varying size was present in lead V5 or V6 in 38 of 45 patients with left axis deviation, and this may account for a low $\mathbf{R}$ wave in left praecordial leads in some patients included in the group of left ventricular hypertrophy. Of 52 patients, $8(15 \%)$ with evidence of 2 nd to 4 th degree left ventricular hypertrophy had a $Q R S$ axis of $-30^{\circ}$ or superior. Therefore, left axis deviation may at least partly depend upon left ventricular hypertrophy in these patients.

Left axis deviation was occasionally associated with considerably raised total pulmonary resistance (Gigli and Scotti, 1952; Grant, 1956). If 7 or more units indicates a critical level of pulmonary vascular disease (Bentall et al., 1959) this was found in 5 patients in this group. In 3 of them a large infracristal defect, $25 \mathrm{~mm}$ to $50 \mathrm{~mm}$ in diameter, was found, and 2 had multiple ventricular septal defects. The dependence of $R / S$ ratio in lead VI upon right ventricular systolic pressure was of borderline significance $(P<0.05)$ in 39 patients with left axis deviation and no signs of pulmonary stenosis, but not significant upon total pulmonary resistance in 27 patients, respectively.

When a continuous gradation was made in patients with right ventricular hypertrophy and pulmonary hypertension and in those with left ventricular hypertrophy and left-toright shunt, the dependence of ventricular hypertrophy upon the haemodynamic measurements was significant in varying degree in patients with left axis deviation and also in patients with a normal axis. In patients with right axis deviation this dependence was not a constant finding, possibly consistent with the relative hypertrophy of the right ventricle found normally in this age group. Hence, left axis deviation is not an absolute contraindication to severe pulmonary vascular disease and 
cannot be used to differentiate the individual patients. Further, evidence of the occasional association of the two findings is given in Table 5, where a highly significant difference at 0.1 per cent level was obtained in the pulmonary artery mean pressure and total pulmonary resistance in patients with right axis deviation and severe pulmonary vascular disease and in those with obvious or extreme left axis deviation. Myocardial disease could probably give rise to this simultaneous occurrence but there was no evidence of it.

I wish to thank Professor J. F. Goodwin for his permission to carry out this investigation and for his helpful advice and criticism throughout the study. I am also grateful to Dr. C. M. Oakley for valuable suggestions. I finally acknowledge Mrs. L. Oranen for statistical analysis.

\section{References}

Bayley, R. H. (1943). On certain applications of modern electrocardiographic theory to the interpretation of electrocardiograms which indicate myocardial disease. American Heart fournal, 26, 769.

Becu, L. M., Fontana, R. S., DuShane, J. W., Kirklin, J. W., Burchell, H. B., and Edwards, J. E. (1956). Anatomic and pathologic studies in ventricular septal defect. Circulation, 14, 349.

Bentall, H. H., Melrose, D. G., Cleland, W. P., Goodwin, J. F., and Hollman, A. (I959). The influence of pulmonary vascular disease upon the results of closure of ventricular septal defect. In Proceedings of the British Cardiac Society. British Heart fournal, 21, 580 .

Beregovich, J., Bleifer, S., Donoso, E., and Grishman, A. (1960). The vectorcardiogram and electrocardiogram in ventricular septal defect; with special reference to the diagnosis of combined ventricular hypertrophy. British Heart fournal, 22, 205.

Blondeau, M., Maurice, P., and Lenégre, J. (1964). L'électrocardiogramme dans la communication interventriculaire. Archives des Maladies du Coeur et des Vaisseaux, 57, 393.

Brink, A. J., and Neill, C. A. (1955). The electrocardiogram in congenital heart disease. With special reference to left axis deviation. Circulation, 12, 604 .

Burch, G. E., and DePasquale, N. (1960). The electrocardiogram, spatial vectorcardiogram, and ventricular gradient in congenital ventricular septal defect. American Heart fournal, 60, 195.

Burch, G. E., and DePasquale, N. P. (1967). Electrocardiography in the Diagnosis of Congenital Heart Disease, p. 3r. Lea \& Febiger, Philadelphia.

Burchell, H. B., DuShane, J. W., and Brandenburg, R. O. (I960). The electrocardiogram of patients with atrioventricular cushion defects (defects of atrioventricular canal). American fournal of Cardiology, 6, 575.

Castellanos, A., Jr., and Lemberg, L. (1969). Reevaluation of septal activation in the human heart. American Heart fournal, 78, 575.

Coleman, E. N. (I962). Ventricular hypertrophy and the electrical axis of the QRS complex in infancy. British Heart fournal, 24, 139.

Durrer, D. (1968). Electrical aspects of human cardiac activity: A clinical-physiological approach to excitation and stimulation. Cardiovascular Research, 2, $\mathbf{I}$.
Feldt, R. H., DuShane, J. W., and Titus, J. L. (1966). The anatomy of the atrioventricular conduction system in ventricular septal defect and tetralogy of Fallot: correlations with the electrocardiogram and vectorcardiogram. Circulation, 34, 774.

Gigli, G., and Scotti, G. (1952). Unusual electrocardiogram in chronic pulmonary disease. Acta Cardiologica, 7, 207.

Goodwin, J. F. (1960). Electrocardiography. In Clinical Disorders of the Pulmonary Circulation, p. I80. Ed. by R. Daley, J. F. Goodwin, and R. E. Steiner. J. \& A. Churchill, London.

Goodwin, J. F., and Abdin, Z. H. (1959). The cardiogram of congenital and acquired right ventricular hypertrophy. British Heart fournal, 21, 523.

Grant, R. P. (1956). Left axis deviation. An electrocardiographic-pathologic correlation study. Circulation, 14, 233.

Gup, A. M., Franklin, R. B., and Hill, J. E. (I965). The vectorcardiogram in children with left axis deviation and no apparent heart disease. American Heart fournal, 69, 619.

Harlan, W. R., Jr., Graybiel, A., and Osborne, R. K. (1965). Determinants of cardiovascular disease in a young population. American fournal of Cardiology, 15, 1 .

Hecht, H. H. (1946). Potential variations of the right auricular and ventricular cavities in man. American Heart fournal, 32, 39.

Hollman, A. (1958). Electrocardiographic diagnosis of right ventricular hypertrophy in infancy and childhood. British Heart fournal, 20 , 129.

Holzmann, M. (1961). Klinische Elektrokardiographie, p. 345. Georg Thieme, Stuttgart.

Kulbertus, H. E., Coyne, J. J., and Hallidie-Smith, K. A. (1969). Conduction disturbances before and after surgical closure of ventricular septal defect. American Heart fournal, 77, 123.

Lambert, E. C., Kelsch, J. V., and Vlad, P. (1963). Differential diagnosis of ventricular septal defect in infancy: a common problem. American fournal of Cardiology, 11, 447.

Leachman, R. D., and Wolfe, R. R. (1968). Isolated ventricular septal defect with counterclockwise inscription of the frontal plane QRS. Cardiovascular Research Center Bulletin, 7, 33.

Lepeschkin, E. (I95I). Modern Electrocardiography, Vol. I, p. 70. Williams \& Wilkins, Baltimore.

Lev, M. (1960). The architecture of the conduction system in congenital heart disease. III. Ventricular septal defect. Archives of Pathology, 70, 529.

Medrano, G. A., De Micheli, A., Cisneros, F., and Sodi-Pallares, D. (I970). The anterior subdivision block of the left bundle-branch of His. I. The ventricular activation process. Fournal of Electrocardiology, 3, 7 .

Pagnoni, A., and Goodwin, J. F. (1952). The cardiographic diagnosis of combined ventricular hypertrophy. British Heart fournal, 14, 451 .

Prato, G. H., and Bouchard, F. (1964). Les communications interventriculaires avec axe électrique gauche. Archives des Maladies du Coeur et des Vaisseaux, 57, 50.

Pryor, R., and Blount, S. G. (1966). The clinical significance of true left axis deviation. Left intraventricular blocks. American Heart fournal, 72, 391.

Romhilt, D. W., Bove, K. E., Norris, R. J., Conyers, E., Conradi, S., Rowlands, D. T., and Scott, R. C. (1969). A critical appraisal of the electrocardiographic criteria for the diagnosis of left ventricular hypertrophy. Circulation, 40, 185.

Rosenbaum, M. B., Elizari, M. V., Lazzari, J. O., Nau, G. J., Levi, R. J., and Halpern, M. S. (I969). Intraventricular trifascicular blocks. The syndrome of right bundle-branch block with intermittent left 
anterior and posterior hemiblock. American Heart Fournal, 78, 306.

Sokolow, M., and Lyon, T. P. (1949). The ventricular complex in right ventricular hypertrophy as obtained by unipolar precordial and limb leads. American Heart fournal, 38, 273.

Titus, J. L., Daugherty, G. W., and Edwards, J. E. (1963). Anatomy of the atrioventricular conduction system in ventricular septal defect. Circulation, 28, 72.

Toscano-Barboza, E., and DuShane, J. W. (1959) Ventricular septal defect. Correlation of electro- cardiographic and haemodynamic findings in 60 proved cases. American fournal of Cardiology, 3, 721.

Wershing, J. M., and Walker, C. H. M. (1963). Influence of age, sex, and body habitus on the mean QRS electrical axis in childhood and adolescence. British Heart fournal, 25, 601.

Requests for reprints to Dr. Heikki Bäckman, Department of Medicine, Central Hospital, Mikkeli, Finland. 